\title{
Regulatory effect of miR-421 on humeral fracture and heterotopic ossification in elderly patients
}

\author{
CHUNFANG JU ${ }^{1 *}$, ZHIYUN LV $^{2 *}$, CHENG ZHANG $^{3}$ and YUJUAN JIAO ${ }^{4}$ \\ Departments of ${ }^{1}$ Health Care for The Elderly and ${ }^{2}$ Nursing, Weifang People's Hospital, Weifang, \\ Shandong 261041; ${ }^{3}$ Department of Orthopedics, Shengli Oilfield Central Hospital, Dongying, Shandong 257034; \\ ${ }^{4}$ Department of Anesthesiology, Weifang People's Hospital, Weifang, Shandong 261041, P.R. China
}

Received June 14, 2017; Accepted January 9, 2018

DOI: $10.3892 / \mathrm{etm} .2019 .7146$

\begin{abstract}
The present study aimed to investigate the role of miR-421 and bone morphogenetic protein-2 (BMP-2) in the bone tissues and blood of elderly patients with humeral fractures and heterotopic ossification. A total of 38 patients with humeral fractures, including 16 patients who received surgery within 1-7 days of fracture and 22 patients who received surgery within 8-14 days of fracture, were enrolled. An additional 18 patients who had heterotopic ossification and 26 patients who had humeral fracture and not heterotopic ossification were also included. Bone tissues and blood were collected. Reverse transcription-quantitative polymerase chain reaction was performed to determine the miR-421 and BMP-2 mRNA expression levels in the samples. Western blotting and ELISA were performed to detect BMP-2 protein levels in bone tissues and blood, respectively. Dual-luciferase reporter assays were performed to verify whether BMP-2 is the direct target gene of miR-421. Compared with the patients who received surgery 1-7 days after fracture, the patients who accepted the surgery 8-14 days after fracture had significantly increased levels of BMP-2 mRNA and protein in their bone tissues and blood $(\mathrm{P}<0.05)$. Contrastingly, the expression level of miR-421 decreased in the samples from patients who accepted the surgery 8-14 days after fracture compared with the level in those who received surgery 1-7 days after fracture $(\mathrm{P}<0.05)$. Compared with the patients without heterotopic ossification, the patients with heterotopic ossification had increased BMP-2 mRNA and protein expression levels in their bone tissues and blood, whereas the expression of miR-421 was significantly decreased $(\mathrm{P}<0.05)$. The dual-luciferase reporter
\end{abstract}

Correspondence to: Professor Yujuan Jiao, Department of Anesthesiology, Weifang People's Hospital, 151 Guangwen Street, Weifang, Shandong 261041, P.R. China

E-mail: yujuanjiao0527@126.com

*Contributed equally

Key words: miR-421, humeral fracture, bone morphogenetic protein-2, heterotopic ossification assay demonstrated that BMP-2 was the direct target gene of miR-421. The upregulation of BMP-2 may be associated with the downregulation of miR-421. miR-421 may regulate the recovery of humeral fracture and heterotopic ossification through BMP-2. The results of the present study may provide a theoretical basis for the diagnosis and treatment of humeral fracture and heterotopic ossification.

\section{Introduction}

Humeral fractures are common and account for $5 \%$ of total body fractures (1). Of the total cases of humeral fractures, $\sim 80 \%$ are non-displaced or slightly displaced stable fractures that do not require surgical treatment (2). Displaced unstable proximal humeral fractures are usually treated surgically (3). Heterotopic ossification refers to the occurrence of ossification outside the bone tissue, and surgery-complicated or secondary heterotopic ossification is clinically known as traumatic ossifying myositis (4).

Currently, more than a dozen bone morphogenetic proteins (BMPs) have been identified $(5,6)$. BMP-2 was originally recognized as an inducer of bone formation belonging to the transforming growth factor- $\beta$ family (7), and it serves an important role in bone formation $(8,9)$ and fracture healing $(10)$. BMP-2 also has an important role in the ossification process, as it stimulates the differentiation of pluripotent stem cells into osteoblasts and enhances the function of osteoblasts $(6,11,12)$. There are various ways to regulate the expression of BMP-2, in which microRNA (miRNA) have been extensively studied. For example, miR-98 (13), miR-203 and miR-320 (14) have been reported to regulate the expression of BMP-2.

MiRNAs are a class of small RNA molecules 18-22 nt in length. They regulate mRNA translation through specific binding to the 3'-untranslated region (UTR) of the target mRNA and are important post-transcriptional regulators (15). Previous studies have confirmed that miRNA serve important roles in various diseases, including cancer, cardiovascular and endocrine disease $(16,17)$. MiR-421 is cell-growth associated and was discovered in recent years (18). It serves an important role in proliferation, invasion and metastasis of multiple tumors $(18,19)$.

In the present study, the expression levels of BMP-2 in bone tissues and blood of patients with humeral fractures at different 
periods and patients with/without heterotopic ossification following humeral fractures were detected. Bioinformatics analysis was performed to identify miRNA sequences that may regulate BMP-2. To the best of our knowledge, this is the first report to discuss the regulatory effect of miR-421 on BMP-2.

\section{Patients and methods}

Clinical data of patients. In order to investigate the role of BMP-2 and miR-421 in bone fracture, 38 patients who received humeral fracture surgery at the Weifang People's Hospital (Weifang, China) between June 2013 and January 2017 were enrolled in the present study. Among them, 16 patients (5 male and 11 female patients) received surgery within 1-7 days of fracture. Their age range was 60-72 years. There were 22 patients who received the surgery within 8-14 days of fracture, including 9 males and 13 females. Their ages ranged from 61-73 years. Reconstructive and fixation surgery was performed according to the fracture site, and complications, including swelling, dislocation and congestion, were treated with respective drugs (Table I). To investigate the role of BMP-2 and miR-421 in the heterotopic ossification process, 18 patients who were diagnosed with heterotopic ossification in the post-surgical follow-up (14-16 months) and required surgery were also enrolled. Among them, there were 5 males and 13 females. Their age ranged from 60-71 years. Presurgical treatment for these patients was the same as in previous treatments of patients with humeral fractures. Another 26 patients with humeral fractures without heterotopic ossification who had received surgery to remove intramedullary nails due to good healing conditions during the same time period were also included. Among them, there were 10 males and 16 females. Their age range was 60-73 years old. These patients were treated as aforementioned (Table II). Patients with rheumatoid arthritis and long-term hormone treatment were excluded from the present study. Bone tissues and blood were collected from all patients. All of the above patients were clearly diagnosed with humeral fractures or heterotopic ossification by pathology analysis. Prior written informed consent was obtained from all patients and the present study was approved by the ethics review board of Weifang People's Hospital.

Sample collection. Fracture site bone tissues and heterotopic ossification bone tissues were obtained from surgery. The non-heterotopic ossification bone tissues were obtained from the fracture tissues of the fixed plate when it was removed. The bone tissues were immediately stored in liquid nitrogen $\left(-196^{\circ} \mathrm{C}\right)$ and ground into powder for further use. Peripheral blood $(30 \mathrm{ml})$ was collected from the patients following fasting on the day of surgery. Serum was isolated from peripheral blood by centrifugation $\left(200 \mathrm{x} \mathrm{g}, 4^{\circ} \mathrm{C}, 10 \mathrm{~min}\right)$.

Reagents. miRcute miRNA isolation kit, miRcute miRNA first-strand cDNA synthesis kit, miRNA miRcute fluorescent quantitative detection kit (FP401), SuperReal PreMix (SYBR Green) and miRNA first-strand cDNA synthesis kit were all purchased from Tiangen Biotech Co., Ltd., (Beijing, China).
Rabbit anti-human BMP-2 primary antibody (ab14933), $\beta$-actin primary antibody (ab8227), horseradish peroxidase-conjugated goat anti-rabbit secondary antibody (ab6721) and enhanced chemiluminescence (ECL) liquid (ab65623) were all purchased from Abcam (Cambridge, MA, USA). TRIzol agent (10606ES60) was purchased from Yisheng Biological Co., Ltd., (Shanghai, China). A bicinchoninic acid assay (BCA) kit (RTP7102) was purchased from Real-Times Beijing Biotechnology Co., Ltd., (Beijing, China). An miRNeasy Serum/Plasma kit (JL217184) was purchased from Guangzhou Jianlun Biological Technology Co., Ltd., (Guangzhou, China). A Human BMP-2 ELISA kit (ab119581) was purchased from Abcam. Image Lab software (v. 3.0) was free from Bio-Rad Laboratories, Inc., (Hercules, CA, US). All plasmids/agomiR were synthesized by Sangon Biotech Co., Ltd., (Shanghai, China). The pMIR-REPORT ${ }^{\mathrm{TM}}$ miRNA Expression Reporter Vector System (AM5795) was purchased from Ambion (Thermo Fisher Scientific, Inc., Waltham, MA, USA).

Reverse transcription-quantitative polymerase chain reaction $(R T-q P C R)$. Total RNA was extracted from the tissues or blood samples using TRIzol reagent. The integrity of RNA bands was examined by $1 \%$ agarose gel electrophoresis, and the RNA purity was measured by a 260/280 ratio using a spectrophotometer. Following this, RNA was reverse transcribed into cDNA using a miRNA first-strand cDNA synthesis kit. The qPCR reaction solution consisted of $10 \mu 1$ SuperReal PreMix Plus (SYBR-Green), $0.5 \mu \mathrm{l}$ upstream primers, $0.5 \mu \mathrm{l}$ downstream primers, $2 \mu \mathrm{l}$ cDNA and $7 \mu \mathrm{l} \mathrm{ddH}_{2} \mathrm{O}$. The following primer sequences were used: BMP-2 forward, 5'-CCTATATGCTCGACCTGT AC-3' and reverse, 5'-CCCACTCATTTCTGAAAGTTC-3'; and GAPDH forward, 5'-GCACAGTCAAGGCTGAGA AT-3' and reverse, 5'-TGAAGACGCCAGTAGACTCC-3'. The qPCR reaction conditions for BMP-2 were as follows: Pre-denaturation at $95^{\circ} \mathrm{C}$ for $30 \mathrm{sec}$, followed by 39 cycles of $5 \mathrm{sec}$ at $95^{\circ} \mathrm{C}$ and $20 \mathrm{sec}$ at $60^{\circ} \mathrm{C}$. miRNAs were extracted using a miRcute miRNA isolation kit and reverse transcribed with miRcute miRNA first-strand cDNA synthesis kit. For the measurement of miR-421, qPCR was performed using a miRNA miRcute fluorescent quantitative detection kit and the primers listed in Table III. The reaction conditions were as follows: Pre-denaturation at $95^{\circ} \mathrm{C}$ for $5 \mathrm{~min}$, followed by 40 cycles of $15 \mathrm{sec}$ at $95^{\circ} \mathrm{C}, 15 \mathrm{sec}$ at $60^{\circ} \mathrm{C}$ and $10 \mathrm{sec}$ at $72^{\circ} \mathrm{C}$. GAPDH and U6 were used as internal controls. The results were calculated using the $2^{-\Delta \Delta \mathrm{Cq}}$ method (20).

Western blot analysis. Total proteins were extracted from the bone tissues and heterotopic ossification tissues using an E.Z.N.A ${ }^{\circledR}$ Total DNA/RNA/Protein kit (Omega Bio-Tek, Inc., Norcross, GA, USA) and the protein concentrations were determined using a BCA protein assay kit. Following this, proteins $(50 \mu \mathrm{g})$ were separated by $10 \%$ SDS-PAGE and transferred to a polyvinylidene difluoride membrane. The membrane was blocked with 5\% skim milk at room temperature for $1 \mathrm{~h}$. Subsequently, rabbit anti-human BMP-2 primary antibody $(1: 1,000)$ and anti- $\beta$-actin primary antibody $(1: 5,000)$ were added and incubated at $4^{\circ} \mathrm{C}$ overnight. Following washing with TBST, the secondary antibody $(1: 3,000)$ was added and incubated at room temperature for 
Table I. Characteristics of patients with humeral fractures.

No. of days after which surgery was performed following fracture

\begin{tabular}{lcc} 
Clinical characteristics & $1-7$ & $8-14$ \\
\hline Case number & 16 & 22 \\
Age (years) & $65.5 \pm 6.7$ & $66.7 \pm 6.2$ \\
Sex & & 9 \\
Male & 5 & 13 \\
Female & 11 & 7 \\
Fracture cause & & \\
Fall & 6 & 8 \\
Car accident & 12 & 2
\end{tabular}

Treatment

Mannitol dehydration, traction, promoting blood

Mannitol dehydration, traction, promoting circulation with safflower injection

blood circulation with safflower injection

Table II. Characteristics of patients with and without HO.

$\mathrm{HO}$

\begin{tabular}{lcc} 
Clinical characteristics & Yes & No \\
\cline { 2 - 3 } Case number & 18 & 26 \\
Age (years) & $64.5 \pm 7.2$ & $65.1 \pm 7.8$ \\
Sex & 5 & 10 \\
Male & 13 & 16 \\
Female & HO & Intramedullary nail removal \\
Cause of surgery & Untreated prior to surgery & Untreated prior to surgery \\
Treatment & 2-12 weeks after surgery & 2-12 weeks after surgery \\
Time of sampling &
\end{tabular}

HO, heterotopic ossification.

Table III. The primers used in this study.

\begin{tabular}{ll}
\hline Name & \multicolumn{1}{c}{ Sequence $\left(5^{\prime}-3^{\prime}\right)$} \\
\hline U6 forward & GCAAATTCGTGAAGCGTTCCAT \\
U6 reverse & GGGATCAACAGACATTAATT \\
miR-421 forward & TGGAAAACTTCCCGAAGAAC \\
miR-421 reverse & GGGATCAACAGACATTAATT
\end{tabular}

miR, microRNA.

$1 \mathrm{~h}$. The membrane was developed with ECL solution. Image Lab v. 3.0 software was used to analyze the protein bands. The ratio of the gray value of the target protein band to that of the $\beta$-actin band was determined as the relative content of the target protein.

ELISA. ELISA was conducted with a Human BMP-2 ELISA kit, according to the manufacturer's protocol. Briefly, $10 \mu \mathrm{l}$ serum and $40 \mu \mathrm{l}$ diluent were added. Except for the blank wells, $100 \mu 1$ horseradish peroxidase-labeled antibody was added to the wells. The plate was sealed with film and incubated at $37^{\circ} \mathrm{C}$ for $1 \mathrm{~h}$. Following five washes with the provided washing reagent, $50 \mu \mathrm{l}$ of substrate $\mathrm{A}$ and $\mathrm{B}$ were added to each well and incubated at $37^{\circ} \mathrm{C}$ for $15 \mathrm{~min}$. Then, $50 \mu \mathrm{l}$ termination solution was added to each well, and the optical density value at $450 \mathrm{~nm}$ was measured within $15 \mathrm{~min}$.

Prediction of the upstream regulatory miRNA of BMP-2.The target gene prediction software of DIANAmT (Ensemble v84; diana.imis.athena-innovation.gr/DianaTools/index. php?r=mrmicrot/index) (21), miRanda (last modified, August 2010; http://34.236.212.39/microrna/home.do) (22), miRDB (lastmodified,May 2016; mirdb.org/)(23), miRWalk(v2.0;zmf. umm.uni-heidelberg.de/apps/zmf/mirwalk/index.html) (24), RNAhybrid (last modified, September 2017; bibiserv. techfak.uni-bielefeld.de/rnahybrid/) (25), PICTAR4 and PICTAR5 (v4.5; pictar.mdc-berlin.de/) (26), PITA (v6; genie.weizmann.ac.il/pubs/mir07/mir07_data.html) (27), RNA22 (v2.0; cm.jefferson.edu/rna22/) (28) and TargetScan 
(v6.2; targetscan.org) (29) were used to predict the upstream regulatory miRNA of BMP-2.

Dual-luciferase reporter assay. The mutant binding sequence was designed as described previously by Guo et al (30). The wild-type and mutant seed regions of the 3'-UTR of the BMP-2 gene containing the miR-421 binding site were chemically synthesized in vitro. Following the addition of the cleavage sites of SpeI and HindIII at both ends, they were cloned into the pMIR-REPORT luciferase reporter plasmid. The mutated 3'-UTR seed region was used as a control. The seed region sequence for the double luciferase reporter plasmid was constructed as follows: 5'-TAATCAAAAGAAGTATCGGGT TTGTACATAATTTTCCAAAAATTGTAGTTGTTTTCA GTTGTGTGTATTTAAGATGAAAAGTCTACATGGAAG GTTACTCTGGCAAAGTGCTTAGCACGTTTGCTTTTT TGCAGTGCTACTGTTGAGTTCACAAGTTCAAGTCCA GAAAAAAAAAGTGGATAATCCACTCTGCTGACTTTC AAGATTATTATATTATTCAATTCTCAGGAATGTTGCAGA GTGATTGTCC-3'. The bold letters represent the target region, and the mutant sequence was GACAACT in the experiments. The plasmid containing the wild-type or mutant 3'-UTR sequences were transfected into 293T cells (Type Culture Collection of the Chinese Academy of Sciences, Shanghai, China) using liposomes (Lipofectamine ${ }^{\circledR} 3000$; Thermo Fisher Scientific Inc.) and then the agomiR-421-containing plasmid was transfected $(100 \mathrm{nM})$ into the cells. After $24 \mathrm{~h}$ of incubation at $37^{\circ} \mathrm{C}$, each group of cells was lysed according to the manufacturer's instruction of the Dual-Luciferase Reporter Assay system (Promega Corporation, Fitchburg, WI, USA). The luciferase reporter activity was recorded by a GloMax 20/20 luminometer (Promega Corporation), using Renilla luciferase activity as the internal standard.

Statistical analysis. All experiments were performed in triplicate independently. All reported data were processed by SPSS 18.0 (SPSS, Inc., Chicago, IL, USA), and the data was presented as the mean \pm standard deviation. Normality tests were performed for the data. Student's t-tests were used for the comparison between two groups. Multiple groups of measurement data were analyzed by one-way analysis of variance. If the variance was homogeneous, the least significant differences and Student-Newman-Keuls post hoc methods were used; if the variance was heterogeneous, Tamhane's T2 or Dunnett's T3 post hoc methods were used. $\mathrm{P}<0.05$ was considered to indicate a statistically significant difference.

\section{Results}

Expression difference of each indicator at different time periods following fracture

Changes of BMP-2 mRNA expression in bone tissue and blood samples in patients with humeral fractures. To determine the changes of BMP-2 mRNA expression in each sample, RT-qPCR was performed. Compared with the patients who received surgery 1-7 days after fracture, the patients who accepted surgery 8-14 days after fracture demonstrated significantly increased BMP-2 mRNA expression levels in their bone tissues $(\mathrm{P}<0.05)$ and blood $(\mathrm{P}<0.01)($ Fig. $1 \mathrm{~A})$. The different levels of BMP-2 mRNA expression suggests that
BMP-2 is upregulated over time within the two weeks after humeral fracture, which may serve a particular regulatory role in humeral fractures.

Changes of BMP-2 protein expression in bone tissue and blood samples in patients with humeral fractures. To determine the expression of BMP-2 protein in the bone tissue of humeral fractures, western blotting was performed. The patients who accepted surgery 8-14 days after fracture had significantly upregulated BMP-2 protein levels in their bone tissues compared to those observed in patients who received surgery 1-7 days after fracture $(\mathrm{P}<0.01)$ (Fig. 1B).

To determine the expression of BMP-2 protein in the serum of patients with humeral fractures, ELISA was performed. Compared with the patients who received surgery 1-7 days after fracture, the patients who accepted surgery 8-14 days after fracture had significantly elevated BMP-2 protein levels in their serum $(\mathrm{P}<0.01)$ (Fig. 1C), which was consistent with the upregulation trend of mRNA expression. The upregulated BMP-2 protein expression level in the blood may indicate that BMP-2 is released from the injured bone tissues.

Changes of miR-421 expression in bone tissue and blood samples in patients with humeral fractures. To determine the changes of miR-421 expression in each sample, RT-qPCR was performed. The patients who accepted surgery 8-14 days after fracture had significantly decreased miR-421 expression levels in their bone tissue samples $(\mathrm{P}<0.01)$ and blood samples $(\mathrm{P}<0.05)$ compared to those in the patients who received surgery 1-7 days after fracture (Fig. 2). This result suggests that miR-421 may serve a regulatory role in the recovery of the humeral fracture.

Expression difference of each indicator between heterotopic and non-heterotopic ossification

Changes of BMP-2 mRNA expression in bone tissue and blood samples in patients with heterotopic ossification. To determine the BMP-2 mRNA level in each sample, RT-qPCR was performed. Compared with the patients without heterotopic ossification, the patients with heterotopic ossification demonstrated significantly upregulated BMP-2 mRNA expression levels in their bone tissues and blood $(\mathrm{P}<0.01)$ (Fig. 3A). This suggests that BMP-2 is upregulated in heterotopic tissues following humeral fracture, and may serve a particular regulatory role in the disease.

Changes of BMP-2 protein expression in bone tissue and blood samples in patients with heterotopic ossification. To determine the expression of BMP-2 protein expression in heterotopic ossification bone tissue following humeral fracture, western blotting was performed. Patients with heterotopic ossification demonstrated significantly upregulated BMP-2 protein expression levels in their bone tissues, compared with those observed in patients without heterotopic ossification $(\mathrm{P}<0.05)$ (Fig. 3B), which was consistent with the upregulation trend of mRNA.

To determine the expression level of BMP-2 protein in the serum of patients with heterotopic ossification, ELISA was performed. As demonstrated in Fig. 3C, compared with 
A

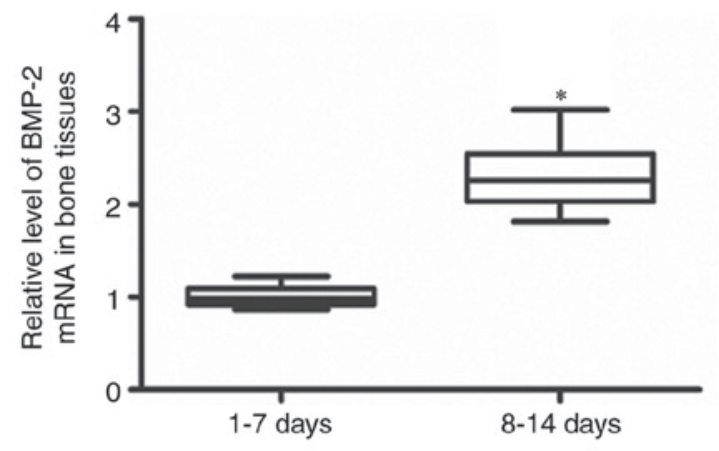

B

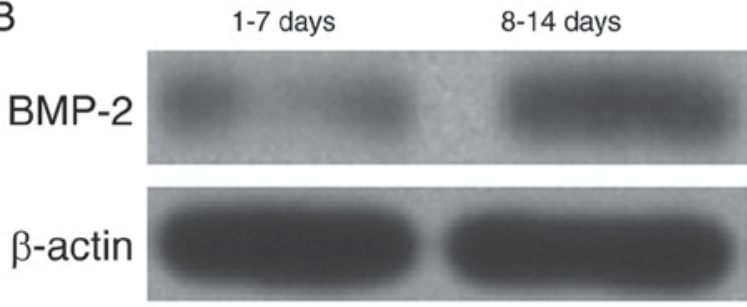

C

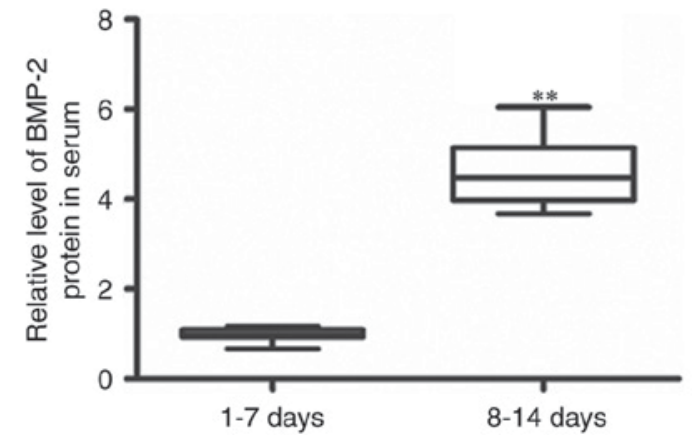

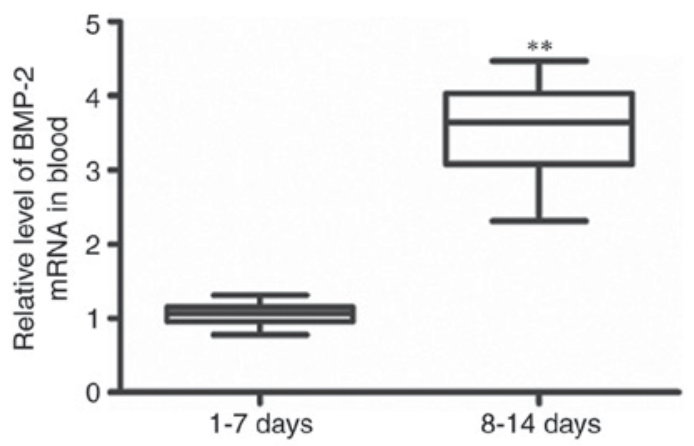

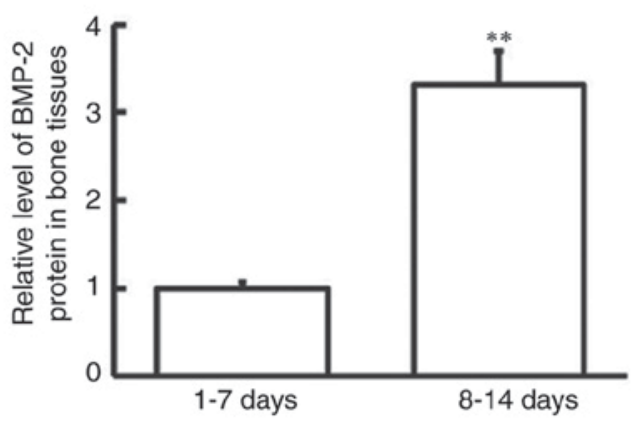

-14 days

Figure 1. Expression levels of BMP-2 mRNA and protein in bone tissues and blood of patients with humeral fractures. Bone tissues and blood were collected from patients who received surgery 1-7 days after fracture and from patients who received surgery 8-14 days after fracture. (A) The expression changes of BMP-2 mRNA in the fracture bone tissues and blood. The expression changes of BMP-2 protein in the (B) fracture bone tissues and (C) serum. Student's t-tests were used for the comparison between two groups. ${ }^{*} \mathrm{P}<0.05$ and ${ }^{* *} \mathrm{P}<0.01$ vs. patients who received surgery $1-7$ days after fracture. BMP-2, bone morphogenetic protein- 2 .
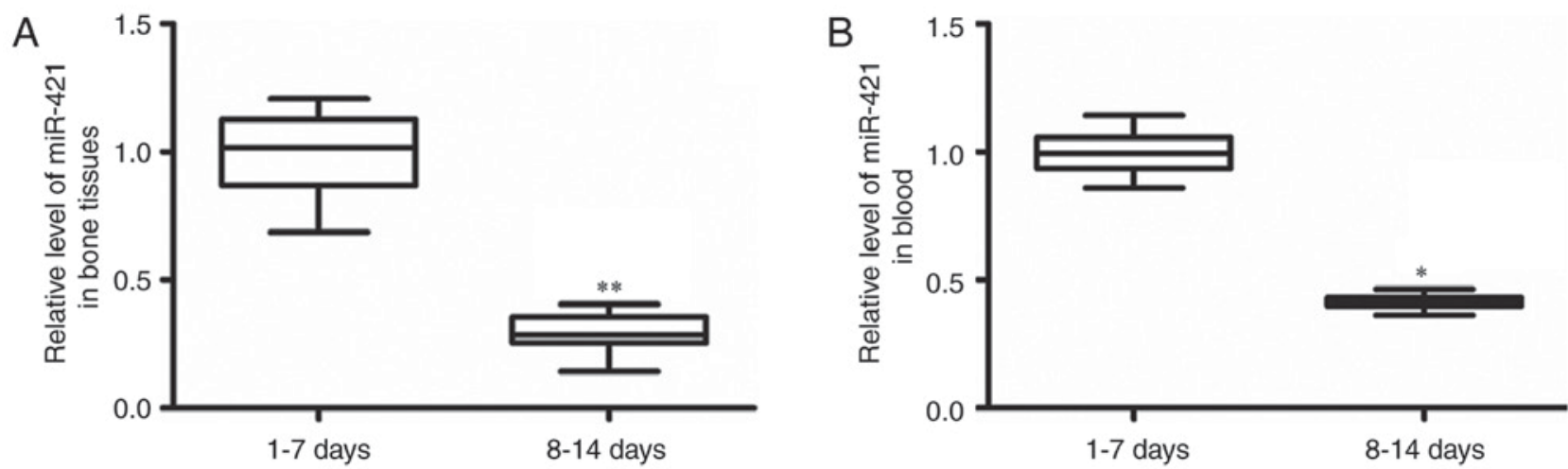

Figure 2. Expression levels of miR-421 in bone tissues and blood of patients with humeral fractures. Bone tissues and blood were collected from patients who received surgery 1-7 days after fracture and patients who accepted surgery 8-14 days after fracture. The expression changes of miR-421 in the (A) fracture tissues and (B) blood are shown. Student's t-tests were used for the comparison between two groups. ${ }^{*} \mathrm{P}<0.05$ and ${ }^{* *} \mathrm{P}<0.01$ vs. patients who received surgery 1-7 days after fracture.

patients that did not have heterotopic ossification, the BMP-2 protein levels were significantly higher in the serum of the patients with heterotopic ossification $(\mathrm{P}<0.05)$. These results suggest that BMP-2 may serve a regulatory role in the recovery of heterotopic ossification at the transcription and protein function levels. 
A

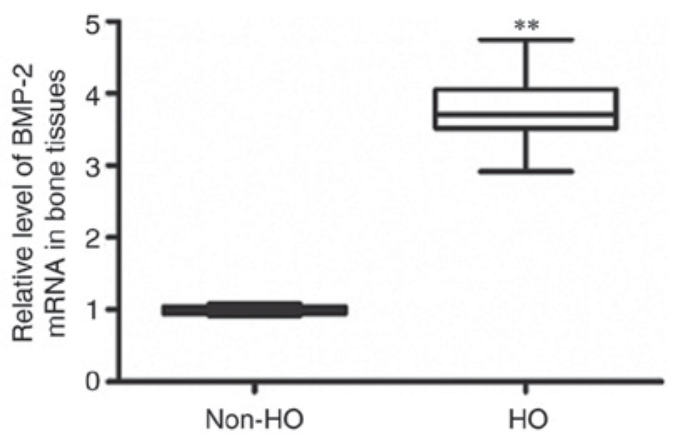

B

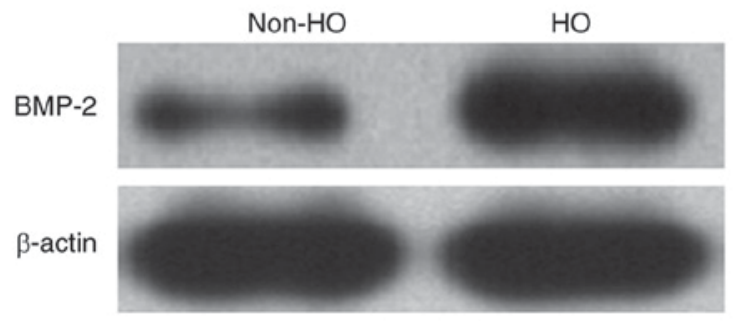

C

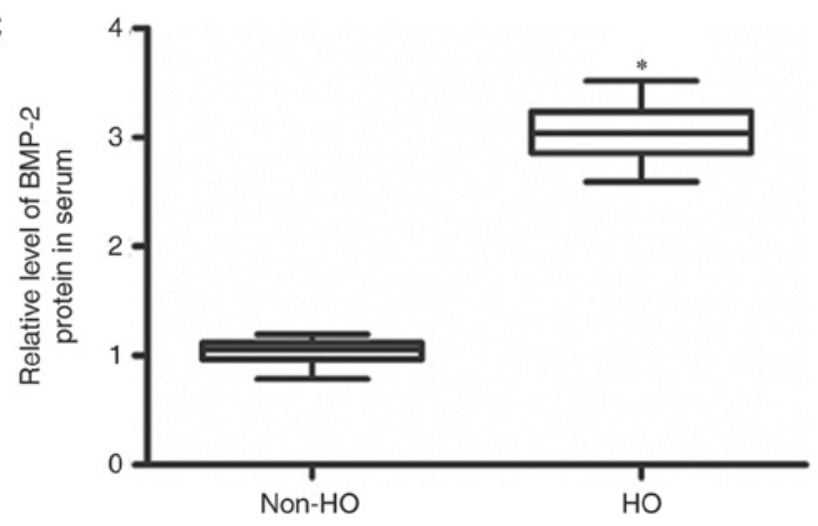

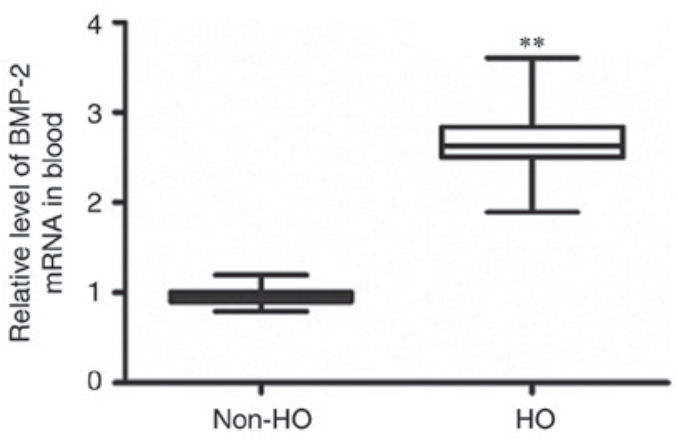

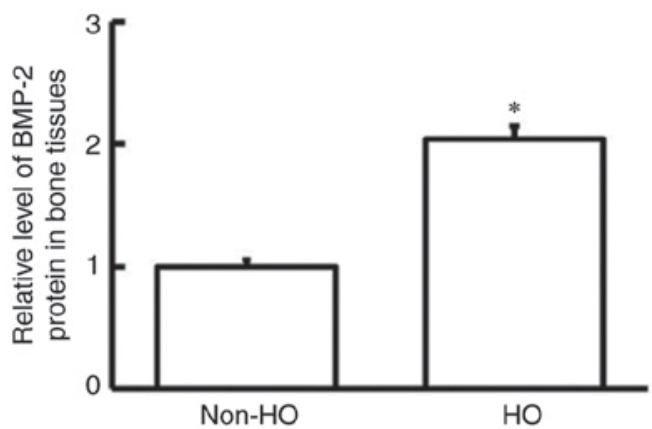

Figure 3. Expression levels of BMP-2 mRNA and protein in bone tissues and blood of patients with and without HO. Bone tissues and blood were collected from patients with $\mathrm{HO}$ and from those without $\mathrm{HO}$ (non-HO). (A) The expression changes of BMP-2 mRNA in the fracture bone tissues and blood. The expression changes of BMP-2 protein in the (B) fracture bone tissues and $(\mathrm{C})$ serum. Student's t-tests were used for the comparison between two groups. ${ }^{*} \mathrm{P}<0.05$ and ${ }^{* *} \mathrm{P}<0.01$ vs. non-HO. BMP-2, bone morphogenetic protein-2; HO, heterotopic ossification.

A

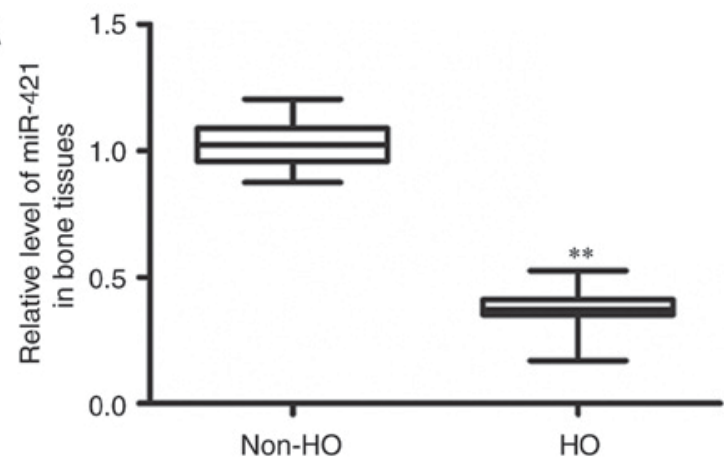

B

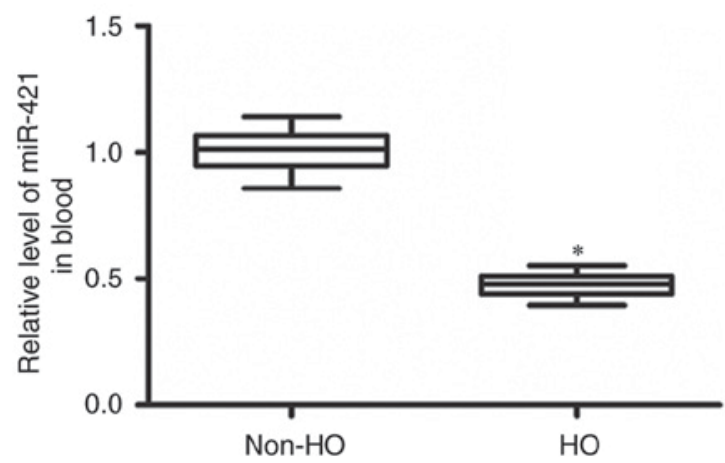

Figure 4. Expression levels of miR-421 in bone tissues and blood of patients with and without HO. Bone tissues and blood were collected from patients with $\mathrm{HO}$ and from those without $\mathrm{HO}$ (non-HO). The expression changes of miR-421 in the (A) fracture tissues and (B) blood are shown. Student's t-tests were used for the comparison between two groups. ${ }^{*} \mathrm{P}<0.05$ and ${ }^{* *} \mathrm{P}<0.01$ vs. non-HO. HO, heterotopic ossification.

Changes of miR-421 expression in bone tissue and blood samples of patients with heterotopic ossification. To determine the expression of miR-421, RT-qPCR was utilized. As indicated in Fig. 4, the patients with heterotopic ossification demonstrated significantly downregulated miR-421 expression levels in their bone tissue samples $(\mathrm{P}<0.01)$ and blood $(\mathrm{P}<0.05)$ compared with those in the patients without heterotopic ossification. This result indicates that miR-421 

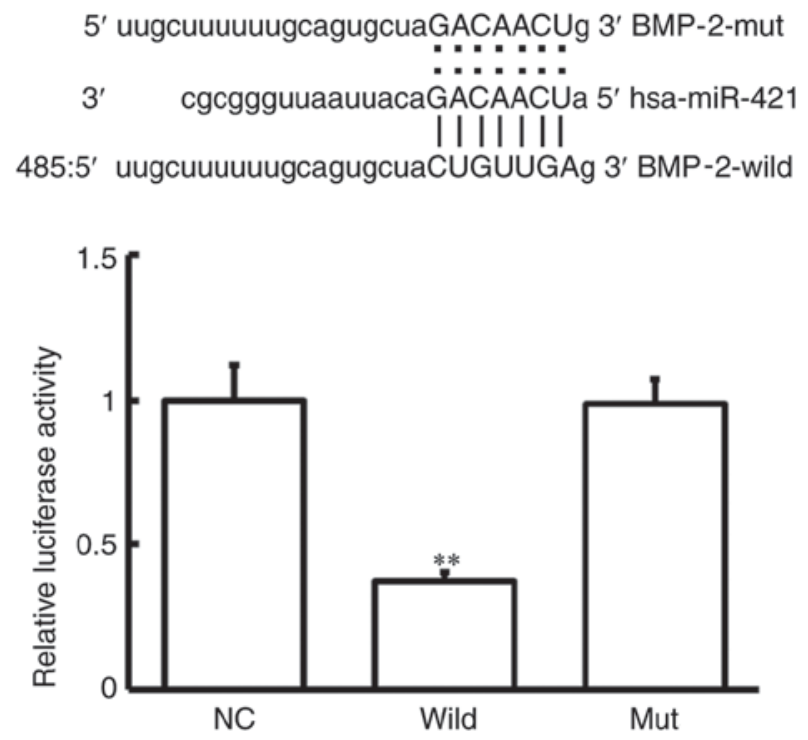

Figure 5. miR-421 targets BMP-2. The wild and mut type binding sequences between BMP-2 and miR-421 are demonstrated on the upper panel. The relative luciferase activity is indicated on the lower panel. One-way analysis of variance was used to compare the measured data of the three groups, and the Student-Newman-Keuls method was used for the pairwise comparison between two groups. ${ }^{* *} \mathrm{P}<0.01$ vs. NC group. BMP-2, bone morphogenetic protein-2; wild, wild-type; mut, mutant; NC, negative control.

may serve a regulatory role in the heterotopic ossification process.

Prediction of miRNA sequences that target BMP-2. To identify miRNA sequences that may target BMP-2, 10 databases were screened. There were 99 sequences predicted from DIANAmT, 303 sequences from miRanda, 11 sequences from miRDB, 117 sequences from miRWalk, 0 sequence from RNAhybrid, 0 sequences from PICTAR4, 241 sequences from PICTAR5, 0 sequences from PITA, 62 sequences from RNA22 and 128 sequences from TargetScan, with a total of 961 sequences predicted as the target genes of miR-421. Apart from the three databases that demonstrated no results, the remaining seven databases predicted BMP-2 as the target gene of miR-421. This high predicting proportion suggests that miR-421 may be the upstream gene of BMP-2. In addition, CUGUUGA was a common sequence of the seed region of miR-421 in the positive databases, indicating that this sequence is highly likely to be the seed region.

miR-421 targets BMP-2. To determine whether the BMP-2 gene was the target gene of $\operatorname{miR}-421$, a dual-luciferase reporter assay was conducted. The wild and mutanttypes ofthe binding sequences between BMP-2 and miR-421 are demonstrated in Fig. 5. The mutant type of binding sequence was designed as described previously by Guo et al (30). Compared with the negative control, the relative luciferase activity was significantly decreased following co-transfection with agomiR-421 and the wild-type 3'-UTR of BMP-2 $(\mathrm{P}<0.05)$, while there was no significant difference observed in the mutant group $(\mathrm{P}>0.05)$. These results indicate that miR-421 may directly bind to the 3'-UTR of BMP-2 and regulate its expression.

\section{Discussion}

Humeral fractures can be complex, and the fracture may combine with fracture-peripheral nerves or blood vessels and cause soft tissue damage, which may lead to impeded blood circulation and neurotrophic disorders, increasing the difficulty of fracture healing (31). Excessive surgical treatment in the case of complex injuries not only destroys the local blood supply of the fracture, but also fails to achieve effective fracture fixation, eventually resulting in the failure of humeral fracture healing (31).

It is well accepted that BMPs are the strongest osteogenic factor, which promotes mesenchymal cells to differentiate into bone, cartilage, ligamentous, tendon and nerve tissues (32). BMP-2 is able to specifically convert mouse myoblast cell lines into osteoblast cell lines $(33,34)$. It is believed that the level of BMP-2 in osteoblasts may reflect its osteogenesis ability $(35,36)$. In the present study, BMP-2 mRNA and protein expression levels in the bone fracture tissue and blood of the patients who received surgery 1-7 days after fracture were significantly lower than those in the patients who received surgery after 8-14 days. This suggests that the body may respond to fracture damage within 2 weeks and then upregulate BMP-2 expression in blood and fracture tissues to induce osteogenesis and repair fracture damages.

Heterotopic ossification is a very important secondary disease following fracture, in which bone structure forms outside the skeletal system (37). It is characterized by rapid formation of calcified bone in the soft tissue, causing swelling and pain around the joints and disorders in joint movement (38). A study by Qu et al (39) suggested that heterotopic ossification required certain incentives, including osteoblasts and an appropriate microenvironment. A study by Mukai et al (40) demonstrated that a decrease of BMP-2 alkaline phosphatase activity served a role in the bone differentiation microenvironment and reduced the occurrence of heterotopic ossification (41). This suggests that heterotopic ossification following fracture may be caused by the fracture-induced overregulation of BMP-2. To verify the role of BMP-2 in heterotopic ossification following humeral fracture, the present study measured the expression of BMP-2 in the ossified tissues and blood of patients with heterotopic ossification. A significantly increased expression level of BMP-2 in the ossified tissues and blood of patients with heterotopic ossification following humeral fractures was observed compared with the levels in patients without heterotopic ossification. This suggests that heterotopic ossification may be related to the upregulation of BMP-2.

Many miRNA have become biomarkers of various diseases (41-43), thus the upstream regulatory miRNA of BMP-2 were also investigated in the present study. The upstream regulatory genes of BMP-2 were predicted by bioinformatics, and miR-421 was identified to be one of them. The expression level of miR-421 in gastric cancer has been previously studied (44). In addition, it has been demonstrated that miR-421 was upregulated in neuroblastoma, pancreatic cancer, prostate cancer and other malignant tumors (45-47). miR-421 is closely related to cell growth. A study by Jiang et al (18) determined that miR-421 expression in gastric cancer tissue was higher than that in normal tissues, indicating that miR-421 may serve an important role in the early growth 
of gastric cancer. A study by Zhou et al (19) detected the expression of miR-421 in peripheral blood mononuclear cell lines by RT-PCR and transfected miR- 421 inhibitors into animals, and found that tumor growth was inhibited. Significant downregulation of miR-421 expression was observed in the humeral fracture and the heterotopic ossification tissue samples in the present study. As aforementioned, BMP-2 mRNA and protein were upregulated in these samples. This suggests that the upregulation of BMP-2 may be regulated by the downregulation of its upstream regulatory gene, miR-421. In the present study, the BMP-2 dual-luciferase gene reporter plasmid was constructed and transfected into 293T cells together with agomiR-421. It was revealed that overexpression of miR-421 could significantly reduce the luminance of the BMP-2 plasmid, demonstrating that BMP-2 is the direct target gene of miR-421.

In conclusion, BMP-2 levels were increased and miR-421 levels were decreased in bone tissue samples and blood of patients with humeral fractures and heterotopic ossification. BMP-2 was a direct target of miR-421. These results indicate that miR-421 may serve an important role in humeral fracture healing through regulating BMP-2. This study may provide a new therapeutic target for fracture and heterotopic ossification.

\section{Acknowledgments}

We would like to thank Dr Weizhi Wang and Dr Xuefang Zhao of the Department of Anesthesiology at the Weifang People's Hospital for guidance and assistance with the experiments.

\section{Funding}

No funding was received.

\section{Availability of data and materials}

The datasets used and/or analyzed during the current study are available from the corresponding author on reasonable request.

\section{Authors' contributions}

CJ, ZL and YJ collaborated to design the study. CJ, ZL and $\mathrm{CZ}$ were responsible for performing experiments. CJ and ZL analyzed the data. All authors collaborated to interpret results and develop the manuscript. The final version of the manuscript has been read and approved by all authors, and each author believes that the manuscript represents honest work.

\section{Ethics approval and consent to participate}

All procedures performed in the current study were approved by the Ethics Committee of Weifang People's Hospital. Written informed consent was obtained from all patients or their families.

\section{Patient consent for publication}

Not applicable.

\section{Competing interests}

The authors declare that they have no competing interests.

\section{References}

1. Court-Brown CM and Caesar B: Epidemiology of adult fractures: A review. Injury 37: 691-697, 2006.

2. Court-Brown CM, Garg A and McQueen MM: The epidemiology of proximal humeral fractures. Acta Orthop Scand 72: 365-371, 2001.

3. Russo R, Cautiero F, Ciccarelli M and Vernaglia Lombardi L: Reconstruction of unstable, complex proximal humeral fractures with the da Vinci cage: Surgical technique and outcome at 2 to 6 years. J Shoulder Elbow Surg 22: 422-431, 2013.

4. Vanden Bossche L and Vanderstraeten G: Heterotopic ossification: A review. J Rehabil Med 37: 129-136, 2005.

5. Barcak EA and Beebe MJ: Bone morphogenetic protein: Is there still a role in orthopedic trauma in 2017? Orthop Clin North Am 48: 301-309, 2017.

6. Krishnakumar GS, Roffi A, Reale D, Kon E and Filardo G: Clinical application of bone morphogenetic proteins for bone healing: A systematic review. Int Orthop 41: 1073-1083, 2017.

7. Dahlin C, Linde A, Gottlow J and Nyman S: Healing of bone defects by guided tissue regeneration. Plast Reconstr Surg 81: 672-676, 1988.

8. Yilgor P, Hasirci N and Hasirci V: Sequential BMP-2/BMP-7 delivery from polyester nanocapsules. J Biomed Mater Res A 93: 528-536, 2010.

9. Ishibe T, Goto T, Kodama T, Miyazaki T, Kobayashi S and Takahashi T: Bone formation on apatite-coated titanium with incorporated BMP-2/heparin in vivo. Oral Surg Oral Med Oral Pathol Oral Radiol Endod 108: 867-875, 2009.

10. Murata M, Maki F, Sato D, Shibata T and Arisue M: Bone augmentation by onlay implant using recombinant human BMP-2 and collagen on adult rat skull without periosteum. Clin Oral Implants Res 11: 289-295, 2000.

11. Bae SJ, Kim HJ, Won HY, Min YK and Hwang ES: Acceleration of osteoblast differentiation by a novel osteogenic compound, DMP-PYT, through activation of both the BMP and Wnt pathways. Sci Rep 7: 8455, 2017.

12. Song R, Wang D, Zeng R and Wang J: Synergistic effects of fibroblast growth factor- 2 and bone morphogenetic protein- 2 on bone induction. Mol Med Rep 16: 4483-4492, 2017.

13. Zhang GP, Zhang J, Zhu CH, Lin L, Wang J, Zhang HJ, Li J, Yu XG, Zhao ZS, Dong W and Liu GB: MicroRNA-98 regulates osteogenic differentiation of human bone mesenchymal stromal cells by targeting BMP2. J Cell Mol Med 21: 254-264, 2017.

14. Laxman N, Mallmin H, Nilsson O and Kindmark A: miR-203 and miR-320 regulate bone morphogenetic protein-2-induced osteoblast differentiation by targeting distal-less homeobox 5 (Dlx5). Genes (Basel) 8: pii: E4, 2016.

15. Jia W, Wu Y,Zhang Q, Gao GE, Zhang C and Xiang Y: Expression profile of circulating microRNAs as a promising fingerprint for cervical cancer diagnosis and monitoring. Mol Clin Oncol 3: 851-858, 2015.

16. Jiang XI, Luo Y, Zhao S, Chen Q, Jiang C, Dai Y, Chen Y and Cao Z: Clinical significance and expression of microRNA in diabetic patients with erectile dysfunction. Exp Ther Med 10: 213-218, 2015.

17. Juzènas S, Saltenienè V, Kupcinskas J, Link A, Kiudelis G, Jonaitis L, Jarmalaite S, Kupcinskas L, Malfertheiner P and Skieceviciene J: Analysis of deregulated microRNAs and their target genes in gastric cancer. PLoS One 10: e0132327, 2015.

18. Jiang Z, Guo J, Xiao B, Miao Y, Huang R, Li D and Zhang Y: Increased expression of miR-421 in human gastric carcinoma and its clinical association. J Gastroenterol 45: 17-23, 2010.

19. Zhou H, Xiao B, Zhou F, Deng H, Zhang X, Lou Y, Gong Z, Du C and Guo J: MiR-421 is a functional marker of circulating tumor cells in gastric cancer patients. Biomarkers 17: 104-110, 2012.

20. Livak KJ and Schmittgen TD: Analysis of relative gene expression data using real-time quantitative PCR and the 2(-Delta Delta C(T)) method. Methods 25: 402-408, 2001.

21. Paraskevopoulou MD, Georgakilas G, Kostoulas N, Vlachos IS, Vergoulis T, Reczko M, Filippidis C, Dalamagas T and Hatzigeorgiou AG: DIANA-microT web server v5.0: Service integration into miRNA functional analysis workflows. Nucleic Acids Res 41 (Web Server Issue): W169-W173, 2013. 
22. Betel D, Wilson M, Gabow A, Marks DS and Sander C: The microRNA.org resource: Targets and expression. Nucleic Acids Res 36 (Database Issue): D149-D153, 2008.

23. Wong N and Wang X: miRDB: An online resource for microRNA target prediction and functional annotations. Nucleic Acids Res 43 (Database Issue): D146-D152, 2015.

24. Dweep H, Sticht C, Pandey P and Gretz N: miRWalk-database: Prediction of possible miRNA binding sites by 'walking' the genes of three genomes. J Biomed Inform 44: 839-847, 2011.

25. Rehmsmeier M, Steffen P, Hochsmann M and Giegerich R: Fast and effective prediction of microRNA/target duplexes. RNA 10 $1507-1517,2004$.

26. Li J, Liang SH and Lu X: Potential role of ezrin and its related microRNA in ovarian cancer invasion and metastasis. Zhonghua Fu Chan Ke Za Zhi 45: 787-792, 2010 (In Chinese).

27. Oliveira AC, Bovolenta LA, Nachtigall PG, Herkenhoff ME, Lemke $\mathrm{N}$ and Pinhal D: Combining results from distinct MicroRNA target prediction tools enhances the performance of analyses. Front Genet 8: 59, 2017.

28. Miranda KC, Huynh T, Tay Y, Ang YS, Tam WL, Thomson AM, Lim B and Rigoutsos I: A pattern-based method for the identification of MicroRNA binding sites and their corresponding heteroduplexes. Cell 126: 1203-1217, 2006.

29. Agarwal V, Bell GW, Nam JW and Bartel DP: Predicting effective microRNA target sites in mammalian mRNAs. Elife 4 2015.

30. Guo W, Qiu Z, Wang Z, Wang Q, Tan N, Chen T, Chen Z, Huang S, Gu J, Li J, et al: MiR-199a-5p is negatively associated with malignancies and regulates glycolysis and lactate production by targeting hexokinase 2 in liver cancer. Hepatology 62 1132-1144, 2015.

31. Zhang Z and Li W: Surgical treatment of upper humerus fracture nonunion. Zhongguo Xiu Fu Chong Jian Wai Ke Za Zhi 24: 673-676, 2010 (In Chinese)

32. Sykaras N and Opperman LA: Bone morphogenetic proteins (BMPs): How do they function and what can they offer the clinician? J Oral Sci 45: 57-73, 2003.

33. Gutierrez J, Osses N and Brandan E: Changes in secreted and cell associated proteoglycan synthesis during conversion of myoblasts to osteoblasts in response to bone morphogenetic protein-2: Role of decorin in cell response to BMP-2. J Cell Physiol 206: 58-67, 2006.

34. Mundy G, Garrett R, Harris S, Chan J, Chen D, Rossini G, Boyce B, Zhao M and Gutierrez G: Stimulation of bone formation in vitro and in rodents by statins. Science 286: 1946-1949, 1999.
35. Su JL, Chiou J, Tang $\mathrm{CH}$, Zhao M, Tsai CH, Chen PS, Chang YW, Chien MH, Peng CY, Hsiao M, et al: CYR61 regulates BMP-2-dependent osteoblast differentiation through the $\{$ alpha\}v\{beta\}3 integrin/integrin-linked kinase/ERK pathway. J Biol Chem 285: 31325-31336, 2010.

36. Dey D, Wheatley BM, Cholok D, Agarwal S, Yu PB, Levi B and Davis TA: The traumatic bone: Trauma-induced heterotopic ossification. Transl Res 186: 95-111, 2017.

37. Muthukumar N: Dural ossification in ossification of the ligamentum flavum: A preliminary report. Spine (Phila $\mathrm{Pa} 1976) 34$ 2654-2661, 2009.

38. Mania VM, Kallivokas AG, Malavaki C, Asimakopoulou AP, Kanakis J, Theocharis AD, Klironomos G, Gatzounis G, Mouzaki A, Panagiotopoulos E and Karamanos NK: A comparative biochemical analysis of glycosaminoglycans and proteoglycans in human orthotopic and heterotopic bone. IUBMB Life 61: 447-452, 2009.

39. Qu X, Chen Z, Fan D, Xiang S, Sun C, Zeng Y, Li W, Guo Z, Qi Q, Zhong W and Jiang Y: Two novel BMP-2 variants identified in patients with thoracic ossification of the ligamentum flavum. Eur J Hum Genet 25: 565-571, 2017.

40. Mukai T, Otsuka F, Otani H, Yamashita M, Takasugi K, Inagaki K, Yamamura $\mathrm{M}$ and Makino $\mathrm{H}$ : TNF-alpha inhibits BMP-induced osteoblast differentiation through activating SAPK/JNK signaling. Biochem Biophys Res Commun 356: 1004-1010, 2007.

41. Gerlach CV and Vaidya VS: MicroRNAs in injury and repair. Arch Toxicol 91: 2781-2797, 2017.

42. Garnero P: The utility of biomarkers in osteoporosis management. Mol Diagn Ther 21: 401-418, 2017.

43. Matsuzaki J and Ochiya T: Circulating microRNAs and extracellular vesicles as potential cancer biomarkers: A systematic review. Int J Clin Oncol 22: 413-420, 2017.

44. Chureau C, Chantalat S, Romito A, Galvani A, Duret L, Avner P and Rougeulle C: Ftx is a non-coding RNA which affects Xist expression and chromatin structure within the $\mathrm{X}$-inactivation center region. Hum Mol Genet 20: 705-718, 2011.

45. Hao J, Zhang S, Zhou Y, Liu C, Hu X and Shao C: MicroRNA 421 suppresses DPC4/Smad4 in pancreatic cancer. Biochem Biophys Res Commun 406: 552-557, 2011

46. Östling P, Leivonen SK, Aakula A, Kohonen P, Mäkelä R, Hagman Z, Edsjö A, Kangaspeska S, Edgren H, Nicorici D, et al: Systematic analysis of microRNAs targeting the androgen receptor in prostate cancer cells. Cancer Res 71: 1956-1967, 2011.

47. Hu H, Du L, Nagabayashi G, Seeger RC and Gatti RA: ATM is down-regulated by N-Myc-regulated microRNA-421. Proc Natl Acad Sci USA 107: 1506-1511, 2010 